\title{
Surgical management of an impacted sharp metallic foreign body in esophagus
}

\author{
Sharma NK, Yadav VK, Pokharna P, Devgaraha S, Mathur RM
}

\begin{abstract}
Introduction: Ingestion of foreign bodies is common and the esophagus is the most common site of impaction in the upper gastrointestinal tract. Case Series: We report two cases of impacted metallic foreign bodies in upper esophagus. The presentating symptoms were throat pain and dysphagia. Rigid and flexible esophagoscopy failed to retrieve the foreign body in both cases hence lateral cervical esophagostomy was performed for foreign body removal. Conclusion: Ingestion of foreign bodies is common. Some metallic foreign bodies frequently get impacted in the esophagus because of their large size, rigidity and pointed edges and are difficult to remove by endoscopy. Therefore, surgery is required for retrieval of such impacted, sharp, metallic foreign bodies.
\end{abstract}

Keywords: Impactation, Lateral cervical esophagostomy, Foreign body

$* * * * * * * * *$

Sharma NK, Yadav VK, Pokharna P, Devgaraha S, Mathur RM. Surgical management of an impacted sharp metallic foreign body in esophagus. International Journal of Case Reports and Images 2013;4(9):463-466.

$* * * * * * * * *$

Sharma $\mathrm{NK}^{1}$, Yadav $\mathrm{VK}^{1}$, Pokharna $\mathrm{P}^{1}$, Devgaraha $\mathrm{S}^{1}$, Mathur $\mathrm{RM}^{1}$

Affiliations: ${ }^{1}$ Department of CTVS, S. M. S Medical College, Jaipur, Rajasthan, India.

Corresponding Author: Dr. Neeraj Kumar Sharma, S. M. S Medical College Jaipur, Rajasthan, India; Email: drneerajji@yahoo.co.in

Received: 24 September 2012

Accepted: 16 November 2012

Published: 01 September 2013
doi:10.5348/ijcri-2013-09-357-CS-1

\section{INTRODUCTION}

Foreign body ingestion is a common problem encountered in clinical practice. Most of them pass spontaneously but some are really problematic. Endoscopic removal of a foreign body is routinely done but it fails in some cases which require surgical removal of the foreign body. We present two cases of unusual foreign body ingestion, one was a sharp metallic folded tin cover and another was a sharp metallic bottle cap. As these foreign bodies could not be retrieved endoscopically, surgical removal of these foreign bodies was performed successfully. Patients are doing well on follow-up after one year.

\section{CASE SERIES}

We report two cases of impacted, sharp, metallic foreign bodies in the upper esophagus. First patient was a 35-year-old male, who was a known case of schizophrenia. He ingested a sharp metallic folded tin cover (Figure 1). The patient presented to us with throat pain and dysphagia. On examination, there was bilateral air entry, equal on both sides, with no added sound. Chest X-ray revealed foreign body in the cervical esophagus (Figure 2). The second patient was a 25-years male. He presented to us with a history of accidental ingestion of sharp metallic bottle cap (Figure 3). At the time of presentation he had throat pain and dysphagia. There was no respiratory distress. On examination chest had bilateral equal air entry without stridor.

In both cases X-ray of the cervical spine and chest (lateral view) were done which reveled foreign body with sharp edges present in the cervical esophagus (Figure 4).

Flexible and rigid esophagoscopy was done for therapeutic removal of the foreign body but failed. Foreign body was impacted in upper esophagus with surrounding inflammation and edema. 
Emergency surgery was planned. Longitudinal incision was given on the left side of neck in front of sternocleidomastoid. Carotid artery and thyroid gland

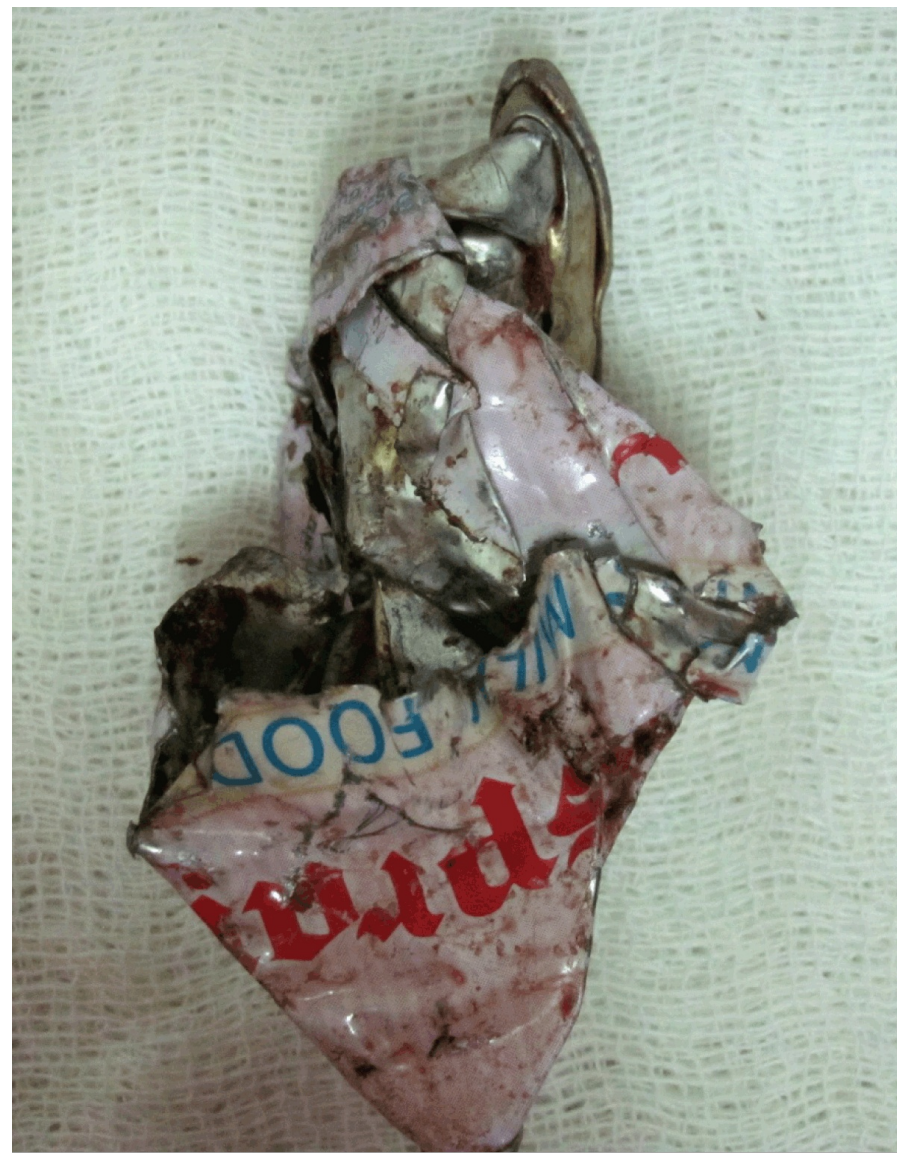

Figure 1: Folded metallic tin cover removed from esophagus (case 1).

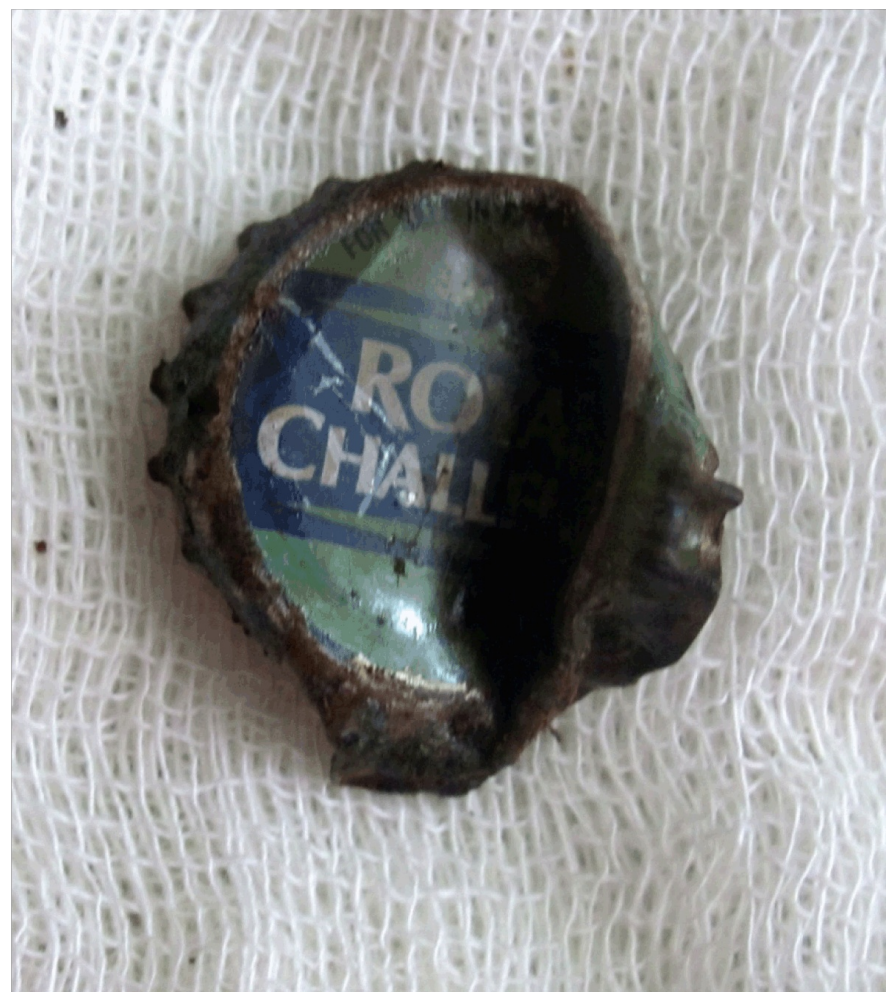

Figure 2: Bottle cap removed from esophagus (case 2). were retracted. Esophagus was found to be inflammed and edematous. Longitudinal incision was given on esophagus over impacted foreign body and foreign body was gently disimpacted and removed to prevent further injury to esophagus. Esophagus was repaired using 3.0 vicryl interrupted sutures in two layers, with Ryle's tube left in situ for three weeks. Postoperative period was

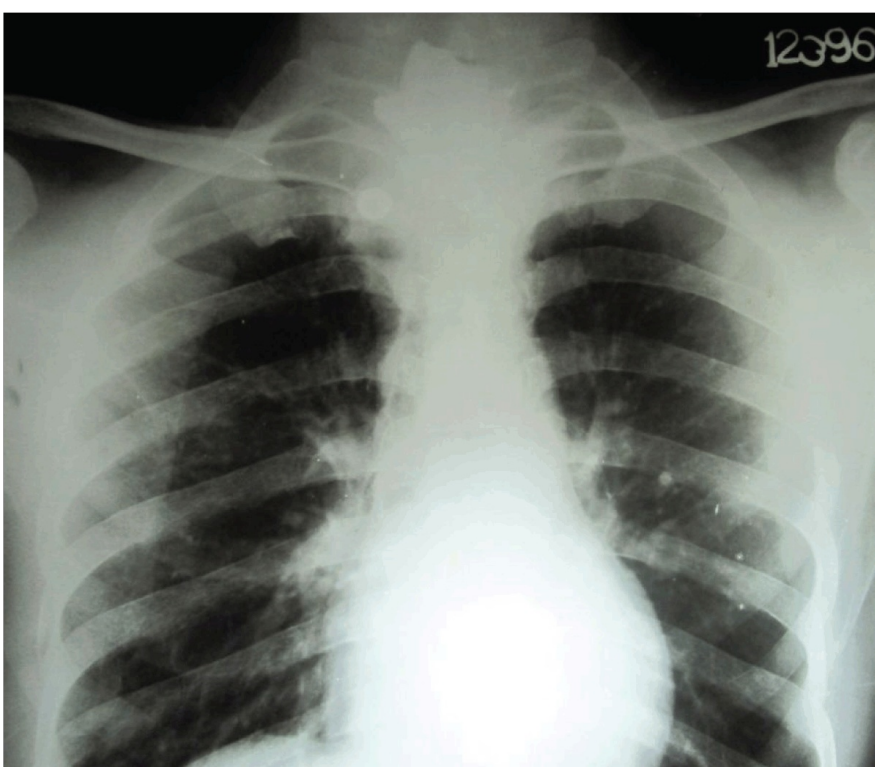

Figure 3: Chest X-ray showing foreign body in the cervical esohagus.

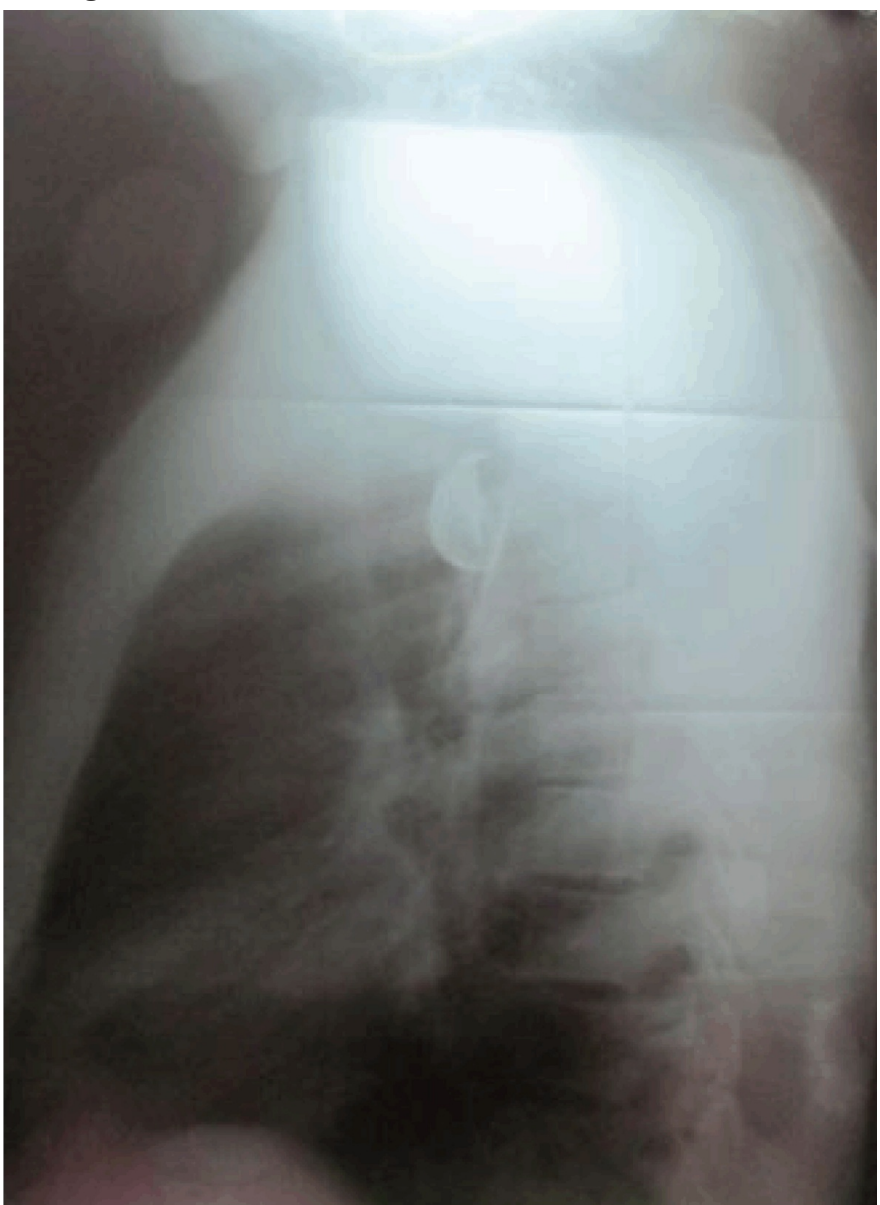

Figure 4: Lateral chest X-ray showing foreign body in the upper esophagus. 
uneventful and both the patients are doing well on follow-up.

\section{DISCUSSION}

It is estimated that up to $90 \%$ of all foreign bodies pass spontaneously from the esophagus. Endoscopic management is needed in less than $10 \%$ cases, whereas surgery is required for foreign body retrieval or management of complications in approximately $1 \%$ patients $[1-3]$. In both our cases, the patients required lateral cervical esophagostomy, after failed endoscopic retrieval.

Although most of the foreign bodies in the gastrointestinal tract are swallowed accidentally, other conditions such as imprisonment, mental illness, mental retardation, bulimia, alcohol consumption or drug abuse may also be involved, particularly in the Western countries [4]. The majority of foreign body ingestions occur in the pediatric population with a peak incidence between six months and six years of age [2-8]. Edentulous adults are also at greater risk for foreign body ingestion, including that of dental prosthesis $[8,9]$. One of our cases had an accidental ingestion of bottle cap while another had a history of mental illness.

Esophageal objects can cause a foreign body sensation, drooling, respiratory distress due to tracheal compression, gagging, dysphonia, vomiting, and dysphagia, depending on the location and nature of the foreign body [10]. Although rare, perforating objects are potentially life threatening because they may lead to the formation of a fistula between the esophagus and the innominate artery thus causing catastrophic bleeding $[11,12]$. Young children and those with mental illness may present with choking, refusal to eat, vomiting, drooling, wheezing, bloodstained saliva, or respiratory distress [5, 7, 13, 14]. Our patients had symptoms of throat pain and dysphagia.

The foreign bodies usually lie close to one of the three esophageal anatomical constrictions: the cricopharyngeal ring, the aortic arch narrowing or the esophagogastric junction $[15,16]$. The most frequent lodgement site of described in literature is the cricopharyngeus muscle $[11,12]$.

Plain films (cervical and chest X-rays) are a very important diagnostic tool, especially in defining the location of the foreign body [10]. A barium-swallow Xray study could be useful in cases of non-radioopaque foreign body, but due to possible barium aspiration and or irritation of the damaged esophageal mucosa, this procedure is no longer used [17-19]. Computed tomography scans can be used to confirm the presence and location of the foreign body (especially in the cases of fish bones), and to evaluate any eventual damage to the neighboring structures $[18,19]$.

In our cases, it was the clinical history, X-rays and endoscopy that guided us in diagnosing and defining the location of the foreign body.

The treatment of choice for esophageal forein bodies depends on various parameters such as patient's age, clinical condition; the type, size, shape, site and number of foreign bodies. [10, 20] Endoscopy is the preferred method with a reported success rate of $83 \%$ [20]. Today, both rigid or flexible endoscopy, performed under general anesthesia or conscious sedation, respectively, are considered to be safe and represent effective methods in experienced hands. For the management of sharp and penetrating foreign bodies, rigid endoscopy is often the treatment of choice. Major risk during esophagoscopy maneuvers include direct instrumental wounds and perforations [16]. Surgical treatment is unavoidable in cases of irretrievable foreign body or esophageal perforation [10].

In our cases, flexible and rigid endoscopies were unsuccessful in the removal maneuvers mainly due to the size and shape of the foreign bodies. Further, the foreign bodies were impacted in esophagus therefore surgical treatment was necessary.

\section{CONCLUSION}

Ingestion of foreign bodies end their lodgment in the esophagus are common. Some metallic foreign bodies get frequently impacted in the esophagus and dose difficulty in endoscopic retrieval due to their large size, rigidity and pointed edges. Therefore in such cases surgery is required for retrieval of the impacted sharp metallic foreign bodies.

$$
* * * * * * * * *
$$

\section{Author Contributions}

Sharma NK - Substantial contributions to conception and design, Analysis and interpretation of data, Drafting the article, Revising it critically for important intellectual content, Final approval of the version to be published

Yadav VK - Substantial contributions to conception and design, Acquisition of data, Drafting the article, Revising it critically for important intellectual content, Final approval of the version to be published

Pokharna P - Substantial contributions to conception and design, Acquisition of data, Revising it critically for important intellectual content, Final approval of the version to be published

Devgaraha S - Analysis and interpretation of data, Revising it critically for important intellectual content, Final approval of the version to be published

Mathur RM - Analysis and interpretation of data, Revising it critically for important intellectual content, Final approval of the version to be published

\section{Guarantor}

The corresponding author is the guarantor of submission.

\section{Conflict of Interest}

Authors declare no conflict of interest. 


\section{Copyright}

(C) Sharma NK et al. 2013; This article is distributed under the terms of Creative Commons Attribution 3.0 License which permits unrestricted use, distribution and reproduction in any means provided the original authors and original publisher are properly credited. (Please see www.ijcasereportsandimages.com/copyright-policy.php for more information.)

\section{REFERENCES}

1. Eisen GM, Baron TH, Dominitz JA, et al. Guideline for the management of ingested foreign bodies. Gastrointest Endosc 2002;55(7):802-6.

2. Webb WA. Management of foreign bodies of the upper gastrointestinal tract: update. Gastrointest Endosc 1995;41(1):39-51.

3. Chaves DM, Ishioka S, Félix VN, Sakai P, GamaRodrigues JJ. Removal of a foreign body from the upper gastrointestinal tract with a flexible endoscope: a prospective study. Endoscopy 2004;36(10):887-92.

4. Lai AT, Chow TL, Lee DT, Kwok SP. Risk factors predicting the development of complications after foreign body ingestion. $\mathrm{Br} \quad \mathrm{J}$ Surg 2003 Dec;90(12):1531-5.

5. Cheng W, Tam PK. Foreign-body ingestion in children in children: experience with 1,265 cases. J Pediatr Surg 1999;34(10):1472-6.

6. Panieri E, Bass DH. The management of ingested foreign bodies in children-a review of 663 cases. Eur J Emerg Med 1995;2(2):83-7.

7. Hachimi-Idrissi S, Corne L, Vandenplas Y. Management of ingested foreign bodies in childhood: our experience and review of the literature. Eur J Emerg Med 1998;5(3):319-23.

8. Blaho KE, Merigian KS, Winbery SL, Park LJ, Cockrell M. Foreign body ingestions in the emergency department: case reports and review of treatment. J Emerg Med 1998;16(1):21-6.

9. Abdullah BJ, Teong LK, Mahadevan J, Jalaludin A. Dental prosthesis ingested and impacted in the esophagus and orolaryngopharynx. J Otolaryngol 1998;27(4):190-4.

10. Athanassiadi K, Gerazounis M, Metaxas E, Kalantzi N. Management of esophageal foreign bodies: a retrospective review of 400 cases. Eur J Cardiothorac Surg 2002;21(4):653-6.

11. Byard RW. Esophageal causes of sudden and unexpected death. J Forensic Sci 2006;51(2):390-5.

12. Tokar B, Cevik AA, Ilhan H. Ingested gastrointestinal foreign bodies: predisposing factors for complications in children having surgical or endoscopic removal. Pediatric Surgery International 2007;23(2)135-9.

13. Kamal I, Thompson J, Paquette DM. The hazards of vinyl glove ingestion in the mentally retarded patient with pica: new implications for surgical management. Can J Surg 1999;42(3):201-4.

14. Chowdhury CR, Bricknell MC, MacIver D. Oesophageal foreign body: an unusual cause of respiratory symptoms in a three-week-old baby. J Laryngol Otol 1992;106(6):556-7.

15. von Rahden BH, Feith M, Dittler HJ, Stein HJ. Cervical esophageal perforation with severe mediastinitis due to an impacted dental prosthesis. Dis Esophagus 2002;15(4):340-4.

16. Karaman A, Cavusoglu YH , Karaman I, Erdogan D, Aslan MK, Cakmak O. Magill forceps technique for removal of safety pins in upper esophagus: a preliminary report. Int $\mathrm{J}$ Pediatr Otorhinolaryngol 2004;68(9):1189-1.

17. Al-Qudah A, Daradkeh S, Abu-Khalaf M. Esophageal foreign bodies. Eur $J$ Cardiothorac Surg 1998;13(5):494-8.

18. Akazawa $\mathrm{Y}$, Watanabe $\mathrm{S}$, Nobukiyo $\mathrm{S}$, et al. The management of possible fishbone ingestion. Auris Nasus Larynx 2004;31(4):413-6.

19. de Lucas EM, Ruiz-Delgado ML, García-Barón PL, Sádaba P, Pagola MA. Foreign esophageal body impaction: multimodality imaging diagnosis. Emerg Radiol 2004;10(4):216-7.

20. Furihata M, Tagaya N, Furihata T, Kubota K. Laparoscopic removal of an intragastric foreign body with endoscopic assistance. Surg Laparose Endosc Percutan Tech 2004;14(4):234-7.
Access full text article on other devices

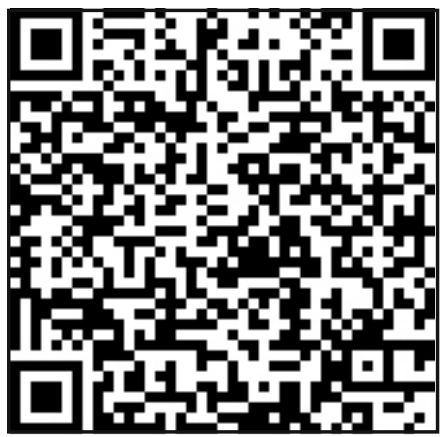

Access PDF of article on other devices

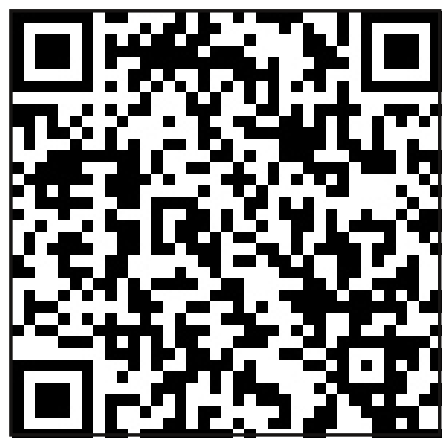

